\title{
Capabilities-Based Defense Planning: Techniques Applicable to NATO and Partnership for Peace Countries
}

\section{Thomas-Durell Young *}

Defense planning, even at its best, is an inexact science. Objective data that demonstrate how well (or poorly) existing and future capabilities will perform on operations as envisaged in the planning process are difficult to come by. And, despite the fact that countries are willing to spend inordinate sums on defense capabilities, the academic and professional literature that addresses defense planning qua planning is modest, in stark contrast with the literature on business planning. ${ }^{1}$ Perhaps unjustified concerns by ministries of defense over the security of information, or simply a lack of general interest by students in the field of strategic studies, have-singularly or combined-produced a rather anemic body of literature dealing with defense planning methodologies. This lack of an objective and normative body of literature on this subject should not, however, be allowed to dissuade defense officials and planners from examining extant approaches to defense planning. To be sure, the range of methodologies from which

Thomas-Durrell Young, Cert., Ph.D., Dipl., is Senior Lecturer and Program Manager for Europe at the Center for Civil-Military Relations at the U.S. Naval Postgraduate School in Monterey. The views expressed in this essay are those of the author and do not necessarily reflect the official policy or position of the Department of the Navy, Department of Defense, or the U.S. Government.

1 The discipline of strategic studies, albeit a relatively new specialty in the field of international relations, is surely an oddity. While exceedingly rich in most areas, the literature of strategic studies has all but ignored addressing, in any generic and systematic sense, the basic issue of how nations should best conduct defense planning. The extant literature on "defense planning," which is indeed prodigious, typically addresses a single country's experience while ignoring any cross-national analysis of methods, let alone attempting to offer generic methodologies that can be adopted by governments, either in their entirety or piecemeal. Surprisingly, there is not a single work in the extant literature that provides a theoretical approach to defense planning, management, and execution, either for didactic purposes, or for application by a government. Instead, particularly in the context of U.S. professional military education, curricula are often developed from source materials that are neither intellectually nor academically rigorous, given their bureaucratic genesis. Moreover, as countries undertake defense reform efforts - a rather prevalent practice, given that the end of the Cold War spawned a large number of young and fragile democracies - there is simply a dearth of work that contains a comprehensive presentation of all of the key contingent elements of defense planning that could serve as an appropriate guide or even template for emulation. This lack of a generic planning approach has a number of debilitating characteristics, not the least of which is that, without such a template, it is exceedingly difficult to demonstrate the benefits of integration, a sine qua non for an efficient and effective planning and execution system. Given that almost all countries have ministries of defense and defense forces, which regularly undergo restructuring and reform, the lack of any rigorous treatment of how nations can improve their planning, management, and execution of the mission of national defense is a significant lacuna in the professional and academic literature. 
one might select may be modest; however, there are sufficient examples of successful planning systems to be studied for emulation.

The present writer has had the unusual opportunity to be able to combine a period of formal academic study with program management responsibilities in the area of defense planning reform. ${ }^{2}$ Given the objective of this special edition of Connections on Partnership Action Plan on Defense Institution Building (PAP-DIB), ${ }^{3}$ instead of addressing a specific case of defense planning reform, this essay will introduce a planning methodology that is discussed (and apparently emulated) but is little understood, particularly as regards its more nuanced aspects. The planning methodology under consideration is "capabilities-based planning." Again, a remarkable fact is that, despite its apparent popularity, the academic and practical literature on capabilities-based planning is modest at best, and non-existent at worst. One might speculate that one explanation for this gap is due to the fact that this methodology appears to be relatively new to North America and Europe. After all, until the early 1990s, NATO and Warsaw Pact countries largely employed variations on threat-based planning - on which there is, not surprisingly, a rather large literature. The excesses of this form of defense planning were, perforce, limited by resource constraints. ${ }^{4}$ However, a Euro-centric myopia in this area can result in overlooking a particular instance where one advanced Western defense establishment undertook, over numerous years of trial and error, the development of a capabilities-based planning methodology. While this is not widely known in NATO and Partnership for Peace countries, Australia experimented with capabilitiesbased planning - that is, planning that is not based on identifiable or quantifiable threats, but rather on the capabilities already present in its armed forces-for over two decades as the basis for designing its force structure. ${ }^{5}$

By the end of the 1980s, after many false starts, the Australian Department of Defense, including the Headquarters Australian Defense Force (HQADF), had developed principles and processes for guiding force development that reflected government strategy and guidance to defend the country, while giving less weight to "threats." In their place, "credible contingencies" were created that were based on capabilities rather than on existing threats. The result of these efforts has been to create a unique

2 See, for example, Aldo Kask, Jaan Murumets, and Thomas-Durell Young, Approaching the Need for Defense Reform: Background and Outlines of Suggested Estonian Defense Planning System, Proceedings 1 (Tartu: Estonian National Defense College, 2003).

3 Euro-Atlantic Partnership Council, "Partnership Action Plan on Defense Institution Building" (PAP-DIB), (Brussels: NATO Information Service, 7 June 2004).

4 For an early attempt to provide NATO defense officials with new planning principles and guidelines, see Ted Greenwood and Stuart Johnson, "NATO Force Planning without the Soviet Threat," Parameters 22:1 (Spring 1992): 27-37.

5 For instance, in a submission before the Australian Parliament's Joint Committee on Foreign Affairs, Defense and Trade, the Department of Defense claimed that the 1971 Strategic Basis paper acknowledged that Australia needed to pursue its own security interests through greater individual effort than had previously been the case. See Australia, Parliament, Joint Committee on Foreign Affairs, Defense and Trade, The Management of Australia's Defense (Canberra: Australian Government Publishing Service [AGPS], 1987), 22-23. 
methodology that made the development of the Australian Defense Force (ADF) more relevant to Australia's enduring strategic circumstances. At the same time, the ADF become more responsive to government guidance and less influenced by particularly service-specific interests and problematic threat scenarios. Thus, the relevance of the Australian experience is that it established guidelines against which the ADF could conceivably operate in a non-threat-specific environment, while making adequate provision for other important planning factors, such as financial limitations.

Notwithstanding the unique characteristics of Australia's geo-strategic situation, the overriding policy requirement that Australian defense planners should come to terms with a threat-ambiguous environment is broadly similar to the imperative now faced by many NATO and PfP countries in the post-Cold War world. Therefore, an examination of the Australian capabilities-based methodology is more than apropos to the subject of PAP-DIB. As such, the purpose of this essay is to describe the Australian defense planning system and its force development methodologies, concluding with an analysis of the lessons learned from Australia that might be useful to other countries. While not all aspects of the process will be relevant elsewhere, the twenty-plus years of experience of the Australian Department of Defense warrants careful examination. At the least, an understanding of this planning methodology could spare defense planners in NATO and PfP nations from making the mistakes that bedeviled their Australian counterparts.

\section{The Defense Planning Process: Content and Outputs}

Any sound defense planning and force development system can only be successfully implemented if there is a modicum of stated and clear government policy to guide planners. To be sure, it is folly for any defense planner to wait for such guidance to be provided in formal documents. Inevitably, it is left to planners to discern guidance from a wide variety of sources, both obvious and obscure. For instance, important guidance for defense planning can be gleaned from such varied sources as a nation's constitution, its defense laws, speeches made by elected government officials, and even press interviews. Indeed, my experience leads to the conclusion that usefulness of these other sources of guidance and priorities can far exceed that of poorly-executed and public relations-oriented national policy documents. In the end, guidance and priorities need to be promulgated in Ministry of Defense-level policy documents that, inevitably, will include such principles as defense of national sovereignty (and, in the NATO context, collective sovereignty), participation in crisis-response operations, etc.

Following the arrival at a clearer understanding of the nation's defense policy guidance and priorities, Australian defense planners established four major steps to be followed in the defense policy process, which will be described generically below. ${ }^{6}$ Some

${ }^{6}$ For background on Australia's defense planning methodology during the period in question, see Paul Dibb, The Conceptual Basis of Australia's Defense Planning and Force Structure Development, Canberra Paper on Strategy and Defense No.88 (Canberra: Strategic and Defense Studies Centre, Australian National University, 1992). 
aspects of this planning process particularly reflect Australia's singular geo-strategic situation, and will therefore be only briefly explained.

First, defense planners need to recognize the fundamentals of a country's geopolitical and geo-strategic setting. While seemingly obvious, a nation's unique geographic characteristics, such as proximity to other countries, population centers, and infrastructure, need be carefully considered in a disciplined and systematic fashion. For instance, in the particular case of Australia, defense planners are confronted with defending an island continent, distant from other countries, that has a vast and climatically inhospitable northern area with limited population and infrastructure. The country also has the advantage of possessing a formidable "air-sea gap" between its northern shores and the islands to its north, which a potential enemy would have to overcome if it wished to threaten Australia. ${ }^{7}$

Second, it is necessary for planners to develop a disciplined and systematic appreciation of the capabilities of the armed forces-both those currently in service and those likely to be procured in the future - possessed by regional states. Officially, these are not threat assessments, but rather surveys of regional defense capabilities, current and anticipated. ${ }^{8}$ Given the nature of the contemporary security environment in the Euro-Atlantic region, a solely geographically-oriented survey could well be replaced by a formal appreciation of terrorist capabilities, the likelihood of natural disasters, etc. In the Australian case, these appreciations were based simply on regional capabilities and did not involve any consideration of (or judgments about) the motives or intentions of other countries in the region. An appreciation of a country's geographic setting and the military capabilities of regional states produce, in effect, warning time and defense preparation requirements. $^{9}$

7 "The area of direct military interest includes Australia, its territories and proximate ocean areas, Indonesia, Papua New Guinea, New Zealand and other nearby countries of the Southwest Pacific." See Australian Department of Defense, Defense of Australia 1987 (Canberra: AGPS, 1987), 2, n. 1; and, more generally, 1-3; 74. Note that this policy of self-reliance does not mean that Australia plans to be self-sufficient in terms of the manufacturing and supply of all defense-related equipment and stocks. See Strategic Review 1993 (Canberra: Department of Defense, December 1993), 75-77. Note that this document superseded Australia's Strategic Planning in the 1990s (Canberra: Department of Defense, 27 November 1989). While those Australian defense officials interviewed emphatically argued that these appreciations were not threat assessments, references to "intelligent adversaries" and the country's "favorable security environment" pre-suppose an evaluation of a "threat," no matter how ill defined. Australian defense officials responded to this observation by stating that their methodology did not allow "threats" to dominate or overly influence their force development methodology.

9 See Dibb, Conceptual Basis, 1-8. 
Third, by combining the findings from the first two steps, a series of credible contingencies and national defense requirements can be generated. ${ }^{10}$ A credible contingency, in effect, is that level of contingency possible given Australia's geo-strategic circumstances and current and foreseeable regional military capabilities, without consideration of motive or intent. Essential elements of these analyses are the capabilities possessed by regional states, their strategic doctrine, level of training and sustainability; the analyses also include an appreciation of the level of conflict one could reasonably expect to confront (e.g., low, low-escalated, medium, etc.). ${ }^{11}$

Australian defense planners argued that these contingencies were not employed as formal threat-based contingency planning, but were developed to produce a baseline against which a country's defense capabilities could be measured in the immediate term. Credible contingencies had a direct influence on developing the ADF's capabilities to meet levels of conflict that could arise in the near term, and the defense expansion base (i.e., reserve forces and expansion of defense industrial capabilities) for conflicts that would take longer to develop. ${ }^{12}$

Fourth, and finally, financial assumptions were introduced. These data were essential to enable the Australian Department of Defense to develop a five-year planning horizon to support and guide force development plans. A key purpose of the defense planning process is to provide vetted force development priorities derived from specific requirements, as opposed to championing "worthy causes." An estimate of the financial resources available for the near future, therefore, is extremely useful for planning purposes. However, particularly in many new NATO members and reforming PfP

10 For greater explanation of credible contingencies see Dibb, ibid., 9-15. Note that these analyses would appear to be similar to the illustrative planning scenarios employed in the U.S. Joint Strategic Planning System. These scenarios suggest, for illustrative purposes, situations in which the United States, perhaps with allies and partners, becomes embroiled in conflict with hypothetical adversaries. These scenarios were described in the Defense Planning Guidance (more recently re-titled as Strategic Planning Guidance) as manifesting military challenges that might be addressed during the Future Years Defense Program. It must be noted, however, that these scenarios are neither predictive, nor exhaustive, regarding those challenges; nor are envisaged as reflecting policy decisions. These caveats aside, these scenarios purportedly illustrate the types of military capabilities needed, enable Department of Defense (DoD) components to perform detailed program planning, provide a basis for ensuring consistency among various DoD component programs, and serve as analytical tools and a base-line for evaluating component programs after they are submitted. See Douglas C. Lovelace and Thomas-Durell Young, U.S. Department of Defense Strategic Planning: The Missing Nexus (Carlisle Barracks, PA: Strategic Studies Institute, U.S. Army War College, 1 September 1995), pp. 7-8, 19-21.

11 Levels of conflict, in Australian usage, are: low-level, escalated low-level, and more substantial conflict. These were defined by Paul Dibb in his Review of Australia's Defense Capabilities (Canberra: AGPS, March 1986), 53-54. Escalated low-level conflict was publicly defined by the Australian government as "the attacker supplementing or substituting unconventional tactics and forces with military units prepared to confront our forces directly." See The Defense of Australia (1987), 24-25.

12 See Dibb, Review of Australia's Defense Capabilities, 16-20. 
nations, such guidance is unlikely. Therefore, financial assumptions will likely need to be developed with a given nation's Ministry of Defense solely for internal planning purposes.

To describe how this planning methodology is translated into reality in Australia, the process produces these conclusions:

- Australia possesses an air-sea gap that is a natural and formidable barrier.

- Australia's regional security assessment is favorable because no identifiable country exists with the intent or ability to threaten fundamental Australian interests, let alone its national security (i.e., to launch and sustain an operation on Australian soil).

- Certain countries do, however, possess capabilities that could be employed against Australia, and these nations' acquisition of more threatening weapon systems could be countered by increasing the ADF's capabilities.

- In the short term and without expansion, such capabilities could be used only in low-level or escalated-low level conflict.

- As a consequence, Australia will defend itself through a strategy of "defense in depth."

These conclusions concerning Australia's geo-strategic environment produced the equivalent of a net assessment and established requirements for the ADF standing force structure and national defense infrastructure. For defense policy, the assessment had the following implications:

1. Given Australia's threat-ambiguous environment, sophisticated intelligencegathering and assessment capabilities are crucial to providing sufficient warning time for an appropriate political response to be made. Clearly, no (sane) government is keen to spend any more than is necessary on national defense (a common theme in contemporary Europe). In consequence, it is assumed that if there exist sufficient intelligence capabilities, government will have sufficient time to act to develop additional capabilities to meet emerging threats.

2. Inhibiting incursions and monitoring Australian sovereign territory and seas require sophisticated air, maritime, and ground surveillance and reconnaissance capabilities, suitable for peacetime and wartime deployment.

3. Priority needs to be placed on building capabilities to meet low and escalatedlow, versus high, levels of conflict. ${ }^{13}$

What this defense policy establishes, therefore, is a practice by which defense officials can approach the definition of missions without accentuating implausible threat scenarios. This is not always an easy objective to fulfill because it is dependent on a relatively high degree of consensus between ministries of defense and their subordinated national defense headquarters - what is, in effect, a critical test of a country's

13 See Strategic Review 1993, 41-49. 
civil-military relations. In consequence, the above procedures provided Australian defense planners with stable direction for developing force structure, which, in principle, structured the ADF for the defense of Australia and in a top-down manner. It should be stressed that, at that time, the sole determinant for structuring the ADF was for the defense of Australia. While the ADF was envisioned as being capable of carrying out other missions - e.g., providing military support to civil authorities, acting in regional interventions, and carrying out alliance/global responsibilities - these tasks in themselves were not allowed to become force structure determinants. ${ }^{14}$

\section{Force Development Methodology}

The previous capabilities-based force development process employed by the Australian Department of Defense and HQADF was divided into three stages (see Figure 1). ${ }^{15}$ However, because the process itself should be understood as a continuum, the distinctions drawn between its three stages are somewhat arbitrary. The stages are: Stage I: Strategic Concepts; Stage 2: Defense Force Capability Options papers; and, Stage 3: Specific Capability Proposals, including Major Capability Submissions. Omitted from this analysis, for the sake of brevity, is any reference to the numerous joint-service and civilian-military committees that assess and adjudicate conflicting requirements and establish priorities throughout the development process.

\section{Stage 1: Development of Strategic Concepts}

Derived directly from the defense planning process, the force development process must first identify the missions the defense force is likely to be required to perform. In addition to constitutional, legal, and policy requirements, the environmental factors conditioning the identification of missions are:

- Relevant key features of a country's geo-strategic situation, such as geophysical aspects and other political, diplomatic, and legal considerations, including technological developments

14 Note that this provision has been the case for some time. The problem, however, was in its implementation prior to the late 1980s. See, Australia, Parliament, Joint Committee on Foreign Affairs, Defense, The Australian Defense Force: Its Structure and Capabilities (Canberra: AGPS, 1984), 63.

15 For an excellent explanation of this process, see the article by Frank Lewincamp, then-Director of the Concepts and Capabilities, Force Development Branch, Department of Defense, "Strategic Guidance and Force Structure: The Force Development Process," FDA Presentation to Acquisition and Logistics Project Management Course, Canberra, 21 July 1992. The process is fully explained in Australia, Department of Defense, Defense Instructions (General), ADMIN 05-1 (The Force Development Process), 23 December 1991, 3. A summary is found in Australia, Department of Defense, Concepts and Capabilities Section, Force Development Branch, "The Force Development Process: From Strategic Guidance to Specific Capability Proposals-A Summary," revised 6 May 1993. Note that all of these documents are unclassified. 
- Current and projected regional military capabilities, including their nature and level of potential threat

- Their potential employment by an intelligent adversary.

A Strategic Concept developed from this analysis will consist of a list of derived tasks to support the identified mission of the Australian Defense Force, including: specification, in the greatest possible detail, of task parameters that include (but are not limited to) rates of effort, location, and duration/sustainability; and, wherever possible, initial judgments of task priorities. In short, Strategic Concepts specify the military tasks that will be needed to support identified missions that are likely to be required of the defense force. It is essential that these tasks be identified correctly and comprehensively in the development process, because they will form the subsequent basis for force development. Once they have been articulated in Strategic Concepts, the tasks identified raise the following questions:

- What has to be done?

- Where must the task be done?

- When and how many times must the task be done?

- How long will the task have to be done?

Note that, at this particular stage, tasks specified in Strategic Concepts are conceptual, and do not specify how missions are to be accomplished. For illustrative purposes, there were eight formal Strategic Concepts developed out of the Strategic Review 1993, which clearly identified eight specific roles for the ADF. ${ }^{16}$ It is important to note that they were developed to ensure a joint force focus so as to complement the various service capabilities of the ADF. The eight Strategic Concepts were:

1. Intelligence collection and evaluation

2. Surveillance of maritime areas and northern Australia

3. Maritime patrol and response

4.Protection of shipping, offshore territories, and resources

5. Air defense within Australia's maritime areas and northern approaches

16 See Strategic Review 1993, 45; 61-67 (Annex A). Note that these were superseded following another review in 1997. The revised hierarchy was structured as:

- Priority One: The knowledge edge (intelligence; command arrangements and command support systems; surveillance of our maritime approaches)

- Priority Two: Defeating threats in our maritime approaches (air superiority; defeating ships)

- Priority Three: Strike

- Priority Four: Land forces (defeating hostile land forces on Australian territory; surveillance of land targets; response).

See Department of Defense, Australia's Strategic Policy (Canberra: Directorate of Publishing and Visual Communications, December 1997, DPUBS: 29785/97), 56-66. 


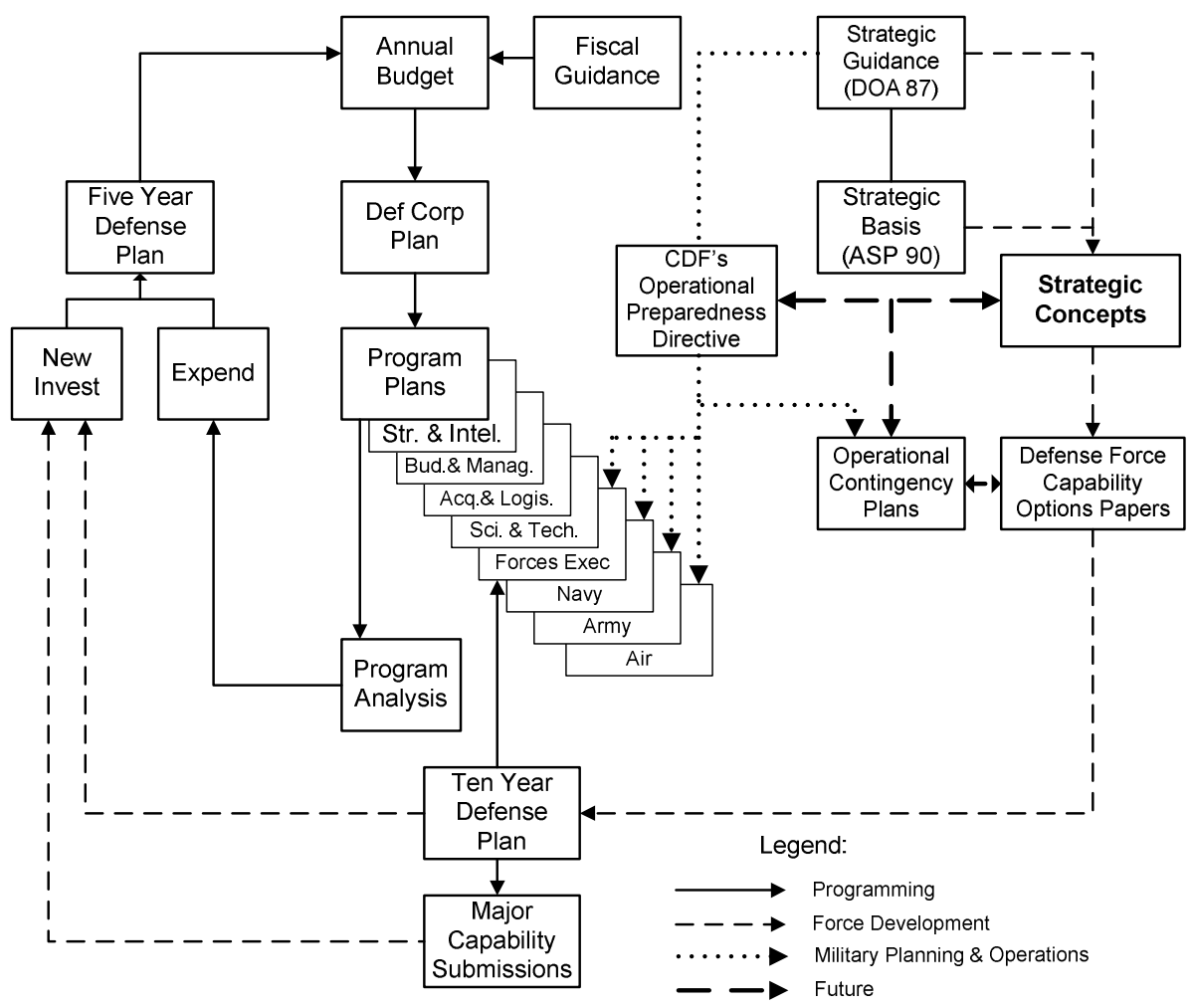

Figure 1: Defense Policy, Planning, and Programming System

6. Defeat of incursions on Australian territory

7.Protection of important civilian and defense assets, including infrastructure and population centers

8. Strategic strike. ${ }^{17}$

Strategic Concepts were never envisioned to be static, and were expected to be reviewed, revised, and revalidated over time as policy, technology, and the geo-strategic situation changed. ${ }^{18}$ Moreover, once all required Strategic Concepts were developed and endorsed, it was foreseen that one master Strategic Concept should be developed in order to provide macro-level context to the documents.

${ }^{17}$ Cf. Australian Strategic Planning in the 1990s, 28-29. Note that developing a response to operations specific to "South Pacific nations" was dropped in the 1993 strategic review.

18 See Department of Defense, "The Force Development Process: From Strategic Guidance to Specific Capability Proposals." 


\section{Stage 2: Defense Force Capability Options Papers}

This particular stage in the planning methodology examines the extent to which current and approved ADF capabilities are sufficient to undertake the tasks identified in the endorsed Strategic Concepts. Where tasks cannot be completed to a level judged to be sufficient or adequate, an analysis is undertaken to ascertain which broad options should be considered for use in overcoming these deficiencies. (It should be noted that this is not an original methodology; its earliest origins can be found in the management reforms implemented in the U.S. Department of Defense during the McNamara era. ${ }^{19}$ A key element of these reforms was the introduction of economic decision-making techniques to the capabilities-requirements process. In an ideal world, such analysis should be based upon clear metrics that measure performance, derived from the results of a formal operational planning process. ${ }^{20}$ ) This is an important step in the development process because it forces the planning system to examine, in a joint service and civil-military context, what can be accomplished with current capabilities and, failing that, what new capabilities are genuinely necessary.

The development of these analyses involves accomplishing the following steps: ${ }^{21}$

1. Ascertain existing capabilities and assess whether they are relevant to the task in question. This analysis must estimate the performance likely to be achieved from using all existing capabilities. This finding is important because it will provide the baseline against which the cost of adjustment options can be measured.

2. Make initial judgments about the acceptable level of performance of capabilities and assess the consequences of not being able to execute tasks to that level, i.e., does a deficiency need to be overcome? This analysis must also consider the likely operational implications of not being able to undertake the tasks completely.

3. Explain how the defense force could reduce or limit the deficiency without major financial expenditure, i.e., cost-effective (involving little capital expenditure) adjustments such as changes in doctrine, organizational structures, or changes to existing command authorities and structures.

4.If the defense force cannot fulfill a task identified in a Strategic Concept, the analysis must explain how it could acquire a higher level of proficiency by improving its various components, e.g., increases in manpower, new equipment, expanded individual/unit training, etc.

${ }^{19}$ Charles J. Hitch and Roland N. McKean, The Economics of Defense in the Nuclear Age (Cambridge, MA: Harvard University Press, 1960).

NATO uses such a process for its members and Partnership for Peace nations: Allied Command Operations, Guidelines for Operational Planning (GOP), 1100/SHOPJ/0400-1-1321, June 2004.

${ }^{21}$ See Department of Defense, "The Force Development Process: From Strategic Guidance to Specific Capability Proposals." 
5. Estimate the expected level of improvement needed while assessing the resource implications of such changes in terms of the costs of any such enhancement options, as well as the possible consequences of not being able to perform the tasks to the level already judged acceptable.

6. Finally, establish force development options and priorities based upon the preceding analyses that present the best return for expended resources.

While perhaps lengthy and complicated, this process can be summed up briefly:

- Can the identified tasks be performed now? (This is not only a question of what is present in the current capabilities inventory, but also how well this can be done at the time of the analysis.)

- How much is enough? (If a surplus of capability exists, a decision must be made whether to reduce the current structure in order to shift excess capabilities elsewhere-e.g., shift low-demand forces from the active force to reserve status. If existing capabilities are inadequate, identify where the discernible shortfall exists and what should be done to justify this shortfall.)

- What are the costs and risks? (It should be remembered that costs can take the form of traditional financial costs, as well as "opportunity costs" to the armed forces; as such, they both need to be identified, quantified, and assessed).

- What are the preferred generic options? (It is important that this process not recommend specific capabilities to fill identified gaps. For example, it would be appropriate for such analyses to conclude that a defense force required improved air defense, or anti-armor capabilities. It would be inappropriate for these analyses to recommend acquiring new/more surface-to-air missiles, or new/more main-battle tanks.)

\section{Stage 3: Specific Capability Proposals, Including Major Capability}

\section{Submissions}

Following approval by a senior defense committee of the generic options identified in Stage 2, the final step in the force development process is to determine specific solutions and match available and envisaged future resources with force structure requirements. The questions involved at this stage concern cost, the type and numbers of specific platforms and/or systems envisaged, and the timing of procurement. Once these proposals/submissions are endorsed by political officials, they can be incorporated into the funding or programming process.

\section{Imperfections in the Methodology}

Perhaps because of its sui generis nature, Australian defense officials have long conceded that their defense planning methodology fell slightly short of perfection. Simply trying to effect a full planning and execution cycle proved difficult. Like most planning systems, it was difficult to actually complete a full planning and execution cycle without innumerable recommendations to improve the system being made midstream. In 
consequence, some would argue that the value of the centrality of endorsed Strategic Concepts in providing overall direction to the force development process was never fully validated. It was also not an uncommon criticism to hear that Strategic Concepts were continuously being re-vetted before they could be fully validated by the planning system. In terms of methodological problems associated with Strategic Concepts, the following problematic aspects can be identified:

- A tendency to exaggerate regional defense capabilities and the likely level of conflict (viz., a natural proclivity by some planners to interpret capabilities as "threats" and assume a worst-case scenario).

- A paucity of mid-level ranking officers with the necessary analytical and methodological skills to develop these papers, particularly those capable of adopting a non-traditional approach. This is a clear caveat for PfP nations with limited civilian defense expertise. However, in the end, it is necessary to have such expertise - which must be insulated from outside influence - in order to allow them to base judgments on sound data.

- The need to ensure that such a new and unique planning process as this one is reflected in national command and control arrangements, particularly as they relate to the sensitive issue of joint command concepts over traditional single-service ones.

- The need to ensure that there is a strong and responsive process that links a Chief of Defense's (CHOD's) defense force's operational preparedness guidance to Strategic Concepts and any other deliberate plans, which should include formal operation, concept and functional operation plans.

- The need to ensure the provision (particularly costs) of adequate logistic support is factored into the planning process at the point where "capabilities" have been identified to accomplish required tasks. ${ }^{22}$ From a methodological perspective, whenever possible, such a logistics support assessment should take place early in the Defense Force Capability Options process.

- The miscalculation on the part of some planners of the complexities and difficulties likely to be confronted by a defense force when responding to low-level con-

The lack of development of a methodological approach to the problem of logistically supporting the ADF in this force development process has been surprising. According to Air Marshal J. W. Newham, RAAF, Chief of Air Staff from 1985 to 1987, "In the Force Structure Committee we were trying to get a few extra Harpoon missiles to meet Navy's ships' outfits requirements, plus a few in reserve. The Assistant Secretary FDA [Force Development and Analysis Division] opined that, as we possessed 72 Harpoons, that would be sufficient to knock out all of the ships of all of the neighborhood navies, so we didn't need any more. He'd overlooked that the 72 Harpoons were of little utility if locked away in ships' magazines deployed hither and thither around Australia. The weapons would not be available unless reserves were held and air launch kits were on hand." See Australia's Air Chiefs: The Proceedings of the 1992 RAAF History Conference (Canberra: RAAF Air Power Studies Centre, 14 October 1992), 67. 
flict. In other words, such a level of conflict is likely to be manpower- and combat-service-support intensive, as opposed to high-level conflicts requiring complex and expensive combat capabilities.

As regards Defense Force Capability Options papers, the following challenges have been identified by Australian defense planners:

- Tasks are common to more than one role and, as such, these data need to be factored into the planning process.

- The execution of tasks may require a joint service effort. This is important given that services tend to be individually funded. Therefore, service budgets need to be reflective of the potential need for "joint" capabilities.

- At least in the early phases of the planning process, planners experienced some difficulty in establishing a direct link between these analyses and standing operational contingency plans.

- The development of appropriate criteria for the capability/risk/cost trade-off (i.e., accurately defining acceptable performance standards that are based on metrics).

- Producing objective capability-to-task analyses, so as to better to inform planners and officials in their decision-making.

- The fact that many capabilities involve multiple roles, which leads to further complications in the capability-to-task analysis.

\section{Learning from Australia's Experience}

One might conclude upon reading this brief overview of Australia's defense planning and force development processes that both of these systems are simply intuitive. Such a judgment ignores the fact that the Australian Department of Defense was a pioneer in developing this planning method, and endeavored to ensure that it was the result of a careful attempt to derive force structure by logical, quantitative, and verifiable means. Officials went to great lengths to limit the extent to which simple judgments or preferences were accepted as facts that were based upon dispassionately derived data. Indeed, these processes were not easily developed - it took a rather sophisticated political and defense community twenty years of experimentation to reach a level of adequate performance. Even today, this planning system is not without its shortcomings and, to their credit, Australian defense officials have long been candid in acknowledging weaknesses. Key elements of this discussion included institutional problems that impeded the methodology's implementation and operation, and how they have been addressed, if not satisfactorily solved. Some particularly vexing problems in this regard have been:

- Until the late 1980 s, the defense community was often provided with insufficient or contradictory policy, strategy, and strategic guidance

- The department of defense suffered from inadequate organizational structures 
- The challenges posed by the perennial need to reconcile funding current tasks to achieve readiness with long-range planning requirements to ensure modernization and future advanced capabilities

\section{Lack of Guidance}

As surprising as it may seem, Australia's official strategic thinking evolved slowly from the early 1970s onward. ${ }^{23}$ Between the publication of the 1972 defense white paper and its 1987 counterpart, Australian defense planners were given at best incomplete (and oftentimes contradictory) guidance from political authorities. ${ }^{24}$ It took Dr. Paul Dibb (consultant to the then-Minister for Defense, Kim Beazley), and his seminal review of the ADF's capabilities, to move the government toward articulating and sanctioning an official national-level strategy. ${ }^{25}$ The 1987 defense white paper provided unambiguous guidance, and the government comprehensively stated its national security aspirations and announced its strategy of "defense in depth." The white paper had the effect of clearly limiting the Australian defense establishment's force structure planning to the defense of Australia. ${ }^{26}$

That said, as many defense planners in PfP member states can fully appreciate, inadequate or contradictory national-level policy and guidance can make developing coherent and integrated plans very difficult indeed. An example of how this lack of strategic guidance can adversely affect planning can be seen in institutional disagreements over the level of conflict for which the ADF should be structured. For instance, prior to the release of the 1987 white paper, the department's civilian-led Force Development and Analysis Division (FDA) argued that the ADF should be structured for low-level contingencies - that is, to limit the options available to government by limiting capabilities. The services, on the other hand, stressed the need to operate at the mid- to high-level end of the conflict spectrum (largely in conjunction with allies in multinational formations). FDA was intent upon forcing the services to concentrate their de-

23 See Australia, Department of Defense, Australian Defense Review (Canberra: AGPS, March 1972), 6-10; 37-38; and idem, Australian Defense, November 1976 (Canberra: AGPS, 1976), 10-14. Extracts of these important official documents can be found in Dibb, The Conceptual Basis of Australia's Defense Planning, 70-83.

Dibb, Conceptual Basis, 49-52.

25 See Dibb, Review of Australia's Defense Capabilities, 25; 49-52.

26 The Defense of Australia (1987), 31-32. It should be noted that I have written extensively critiquing this strategy and the policy of "self-reliance," in that it seems inconceivable that defense planning should seek, in effect, to limit possible government options by limiting capabilities. See my review essay of Michael Evans's The Tyranny of Dissonance: Australia's Strategic Culture and Way of War, 1901-2005 (Canberra: Land Warfare Studies Centre, 2005), in The Australian Army Journal 3:1 (Summer 2005-06): 241-47; and my paper, "The Nuanced Australian-U.S. Defense Relationship," Presentation to the Woodrow Wilson International Center for Scholars, Asia Program (1 June 2005), available at http://www.wilsoncenter.org/index.cfm?topic_id=1462\&fuseaction=topics.documents\&grou p_id=28652. 
velopment efforts on building capabilities for the specific mission of the defense of northern Australia, while the services favored the procurement of "high-tech" capabilities better suited for a "blue on red," high-intensity conflict. Obviously, agreement upon which level of conflict will be most relevant to a country's security requirements is critical in acquiring the appropriate capabilities to equip the force. In the case of Australia, this argument was only resolved with the publication of the 1987 defense white paper.

Finally, in 1993, a review of the strategic basis of Australian security was completed: Strategic Review 1993. This document examined the global and regional changes affecting Australia's defense, and identified and established a prioritized list of the principal current and foreseeable tasks of the ADF. Strategic Concepts were subsequently revised or developed based upon the ensuing analysis and priorities generated by this policy document. ${ }^{27}$ While the existence of a stated strategy- "defense in depth," as established in the 1987 defense white paper - went far in providing a framework for development that proved to be extremely useful to implementing planning based upon these Strategic Concepts, the lack of a similar level of clarity in establishing the ADF's new roles and missions in achieving these new objectives had the effect of retarding the implementation of the force development process. As such, initial efforts to (re-)write Strategic Concepts floundered because they tended to be single-service oriented. Subsequent to issuing Australia's Strategic Planning in the 1990s, the ADF adopted nine principal defense tasks in an attempt to develop jointly conceived Strategic Concepts. During this interim period, without any sanctioned strategic guidance, the services were forced to use levels of conflict as guidance. ${ }^{28}$ In essence, the publications Australia's Strategic Planning in the 1990s and Strategic Review 1993 provided unquestionable government-endorsed policy and guidance to be employed in the initial phases of the force development process.

One can thus see that it took a considerable amount of time before the Australian government was able to institute its novel defense planning and force development process. A key lesson from the Australian experience is that a top-down approach was required to overcome institutional opposition (in particular, from the individual services) to implementing the planning process. The Australian experience also demonstrates that, without recognized and accepted national-level government-endorsed guidance - policy, strategic, and financial - a top-down approach to defense planning is very difficult to execute in the presence of opposition from the services and other institutional stakeholders. However, it is also a mistake to conclude from this case study that formal documents are necessary to achieve such a planning methodology. Oftentimes, national-level policy can be found in disparate sources, such as the constitution, defense laws, and speeches by senior civilian officials. It is the task of senior civilian defense officials to gather such guidance and integrate it in a usable form for planning purposes.

27 See Strategic Review 1993, 39-49.

28 Briefing, Department of Defense, Russell Offices, Canberra, ACT, December 1992. 


\section{Inadequate Organizational Structures}

Prior to the reorganization of Headquarters Australian Defense Force (HQADF) in 1990, the Australian defense organization was not well structured to implement a topdown defense planning system. Until the latter half of the 1980s, the armed services were more or less modeled upon their American or British counterparts in key elements of their structure. As in most Western defense forces, little thought or effort had been directed to developing joint capabilities. Moreover, there was a clear predilection on the part of governments, and consequently planners, to direct resources to individual service combat capabilities, as opposed to developing joint capabilities and combat support, and combat service-support, formations. Hence, the Australian services were eminently well suited for combined operations alongside their allied counterparts when forward deployed and within larger allied formations, as opposed to conducting joint and integrated operations with other services from the Australian military, even within Australia. This force structure, while perhaps appropriate to the period of "Forward Defense" in the 1950s and 1960s (when Australian forces were deployed in Southeast Asia), was judged by civilian defense planners and some elected officials as being hopelessly ill-suited to support a new defense policy based upon the premise that defending Australia proper was the top priority for the ADF, and should therefore drive its capability development. ${ }^{29}$

Organizationally, the individual services retained considerable independence from the civilian side of the Department of Defense, including responsibilities for force development. ${ }^{30}$ Indeed, until the consolidation of the civilian sections of the three services into the Department of Defense in 1973, each service had its own individual department and minister! While the 1973 reorganization ${ }^{31}$ has been referred to as the act that "civilianized" the Australian defense establishment, it still left many problems unsolved. ${ }^{32}$ Most significant was that it left the services' force development divisions intact. In consequence, there ensued a lack of advance coordination between the civilian and military defense planning organizations, and a series of joint planning documents went largely ignored by the services. ${ }^{33}$ In fact, the services were often accused by civilian defense planners of simply proposing block replacement of aging equipment, without adequate consideration of their relevance to Australia's defense needs. Indeed, as Dibb observed in 1986,

29 For example, see T.B. Millar, Australia's Defense, 2nd ed. (Carlton, VIC: Melbourne University Press, 1969), 109-45.

30 See The Management of Australia's Defense, 301-2.

31 Australia, Department of Defense, Australian Defense (Report on the Reorganization of the Defense Group of Departments, Presented to the Minister for Defense, Canberra, November 1973).

32 See Robert O'Neill, "Defense Policy," in Australia in World Affairs, 1971-1975, ed. W. J. Hudson (Sydney: George Allen and Unwin, 1980), 24-25.

33 See Wesley H. Schmidt, Jr., Planning Australia's Defense Forces (Newport, RI: Department of National Security Decision Making, U.S. Naval War College, 14 March 1990), 195-96. 
Force structure planning deficiencies have been compounded by the lack of a comprehensive military strategy and operational concepts for the defense of Australia. In the absence of more definitive guidance, each Service has developed its own planning. ...These documents are not coordinated with one another, nor do they necessarily follow closely current strategic guidance. Some of their force structure objectives are unrealistic. $^{34}$

These organizational problems were addressed in 1990 following an important review that restructured the HQADF. This headquarters, which had been established in 1984 to serve as a joint staff, assumed greater authority through the creation of the position of Vice-Chief of the Defense Force, with responsibilities of coordinating force development and long-term planning activities, as well as an Assistant Chief of the Defense Force (Development), with resources drawn from the individual services. ${ }^{35}$ Hence, when viewed in conjunction with the publication of key policy, planning, and strategy documents, the centralization of military force development responsibilities, along with the concentration of civilian expertise in the Force Development Division, established processes that were more conducive to a top-down approach to defense planning and force development.

\section{Reconciling Current Tasks with Long-Range Planning}

A problem that has long plagued Australia, and one that is surely familiar to NATO and PfP member nations, is the challenge of funding current operations while leaving adequate financial resources to acquire long-term capabilities. Moreover, despite their development of a rather sophisticated and structured planning system, Australian politicians and defense officials (the very ones who championed this planning system) have not been averse to bypassing the planning system to purchase weapon systems, thereby defeating the purpose of top-down planning. ${ }^{36}$ The need for farsighted defense investment is particularly important in Australia, which predicates its defense planning upon the critical assumption of sufficient warning time of a developing military threat in order to activate its defense expansion base. The end of the Cold War combined with an extensive (and expensive) capital acquisition program launched in the mid-1980s to place the Department of Defense in the perennially difficult position of needing to fund

${ }^{34}$ Dibb, Review of Australia's Defense Capabilities, 27.

35 See Australia, Department of Defense, Management Improvement and Manpower Policy Division, Report on the Implementation of the Structural Review of Higher ADF Staff Arrangements (Canberra, 1 May 1990), 19-20.

${ }^{36}$ For example, the government's decision in 1993 to purchase fifteen excess USAF F-111 aircraft was made because they were a "good buy." There was no need for these aircraft that had been validated by the planning system. See The Telegraph-Mirror (NSW), 30 June 1993; and The Sydney Morning Herald, 18 September 1993. 
current operations while attempting to find ways to fund long-term capital acquisition projects. $^{37}$

As one can imagine, there is no simple answer to the conundrum of funding current and future activities in an environment of effectively diminishing resources. A review was conducted in 1990-91 to reexamine force development plans and priorities in the light of lower levels of funding than were anticipated in the 1987 white paper. One of the recommendations of this report, Force Structure Review 1991, was that the Department of Defense adopted a ten-year planning system to complement the existing Five Year Defense Program. ${ }^{38}$ This new program's envisaged purpose was to establish necessary longer-term priorities in order to better manage limited resources. While certainly not a panacea, the development of a ten-year development plan was judged somewhat useful in forcing the establishment of clear resource priorities. However, it should be noted that Australian defense officials discovered that an early problem developed in the utilization of this plan, in that it tended to endorse the block replacement of equipment, which is antithetical to the top-down planning process. ${ }^{39}$ Australian defense officials felt that this issue would be resolved once Defense Force Capability Options Papers were sufficiently developed to provide a greater level of specificity to the ten-year development plan.

\section{The End of Capabilities-Based Planning?}

A number of unconnected events appear to have conspired to end, at least in a formalistic sense, the predominance of capabilities-based defense planning in Australia. First, the electoral defeat of the Australian Labor Party in 1996 by a conservative coalition might well have spelled the end of this planning methodology. Notwithstanding the impeccable pro-American credentials of the Labor government (in power since 1983), the new conservative coalition was elected on a platform of improving Australia's defense relationship with the United States. However, it was not until the commissioning of the Defense Efficiencies Review in 1997, and the adoption of its recommendations by the government-including the consolidation and amalgamation of offices within the Department of Defense and HQADF - that power relationships and priorities

${ }^{37}$ For background on this issue see Graeme Cheeseman, "Over-reach in Australia's Regional Military Policy," in The New Australian Militarism: Undermining Our Future Security, ed. Graeme Cheeseman and St. John Kettle (Leichhardt, NSW: Pluto Press Australia, Ltd., 1990), 73-92; and Thomas-Durell Young, "Problems in Australia's 'Defense Revolution,"” Contemporary Southeast Asia 11:3 (December 1989): 237-56.

38 See Australia, Department of Defense, Force Structure Review 1991 (Canberra: AGPS, May 1991). 
changed. ${ }^{40}$ Moreover, the priority to focus the nation's finite defense resources on the "defense of Australia" was replaced by the need to fund capabilities geared toward peace-support operations, such as in East Timor, as well as to support coalition operations in support of the global war on terrorism. It is as yet sufficiently uncertain to conclude whether the planning methodology failed to meet the new policy requirements of the government, or that its implementers were unwilling to adapt it to the new policy environment, or that the new defense organization was incapable of executing the system as previously organized.

\section{Conclusions}

This essay has described and analyzed how, notwithstanding difficulties and challenges, a defense force can be structured on a threat-ambiguous planning basis that reflects government guidance and macro-regional security considerations. The Australian experience has shown that, given proper government guidance on both policy/strategy and funding, a defense force can be developed to meet the objectives established by the government. Leaving aside the specific stages and details of the planning process, the Australian case reveals that a number of institutional and policy conditions are necessary. Top-down planning is particularly dependent upon government guidance: policy leadership, strategic guidance, and financial direction. An appropriate institutional structure is also necessary in order for these directives to be implemented. The Australian experience demonstrates that, without these structures, the planning process between the individual services and the development office can be very contentious and, as a result, often ineffectual. Thus, the creation of a joint headquarters with adequate staffing, headed by a senior military officer, to work with the civilian defense force development officials will also encourage success. One of the additional benefits of such a system is that it tends to encourage and facilitate the joint development of capabilities to meet endorsed tasks.

Obviously, the Australian experience has not been without its own problems and shortcomings, the difficulty of combining the funding requirements of current tasks

40 The Force Structure Review recommended the adoption of an "integrated planning structure, ... able to identify the capability consequences of changes to resource levels and ... to determine the longer term consequences of such changes for force capability." Moreover, the review recommended the need to adopt "longer term planning so as to identify the factors that will shape the Defense Force of the future." See Future Directions for the Management of Australia's Defense, Addendum to the Report of the Defense Efficiency Review: Secretariat Papers (Canberra, Directorate of Publishing and Visual Communications, Defense Centre Canberra, 1997, DPUBS: 27119/97), 21-25, particularly 23. See also Future Directions for the Management of Australia's Defense, Report of the Defense Efficiency Review (Canberra: Directorate of Publishing and Visual Communications, Defense Centre Canberra, 1997, DPUBS: 26975/97); see particularly E-4, recommendation R16: "The Concepts and Capabilities Committee, the Force Structure Policy and Programming Committee and the Defense Source Definition Committee should be disbanded and replaced with competent staff work and ad hoc meetings if necessary." 
with long-term planning being only one example. However, this should not condemn the process itself. At a time when NATO and PfP nations are searching for convincing means to justify existing, let alone new, force structures, proposals based upon methodologies that emphasize threat-ambiguous (or capabilities-based) rationales stand a greater likelihood of obtaining government support than arguments based upon other, more ephemeral rationales. To be sure, not every aspect of the Australian methodology may apply to all states. However, one could make a strong argument that the shifting of force development resources and responsibilities away from the individual services to a joint staff warrants consideration by most NATO and PfP member nations. What may be particularly valuable to some nations are certain elements of the Australian methodology that would increase the intellectual discipline and rigor of their planning processes. At bottom, the Australian methodology requires careful and systematic consideration of what a defense force should be structured to do. It should imbue the defense planning process with an active and practical mentality in what has been, in many instances, a reactive process, one that has been all too vulnerable to challenges by ministries of finance in all too many NATO and PfP nations.

In sum, the Australian experience offers insights into the planning process, successes that other countries can duplicate, and mistakes that they can avoid replicating when introducing reforms to their defense planning methodologies. Without an identifiable threat upon which to focus, defense planning in NATO and PfP nations is a "tough sell" to many politicians, and justifiably so. What responsible political leaders and civilian officials are increasingly demanding from military establishments are wellreasoned justifications for military capabilities that meet stated requirements. A threatambiguous planning process, based upon a review of the twenty-odd years of Australian successes and failures, might be a reasonable place to start developing such processes. 


\section{Bibliography}

Cheeseman, Graeme. "Overreach in Australia's Regional Military Policy." In The New Australian Militarism: Undermining Our Future Security, 73-92. Leichhardt, NSW: Pluto Press Australia, Ltd, 1990.

Evans, Michael. "The Tyranny of Dissonance: Australia's Strategic Culture and Way of War, 1901-2005." The Australian Army Journal 3, no. 1 (1960): 241-47.

Greenwood, Ted, and Stuart Johnson. "NATO Force Planning without the Soviet Threat." Parameters 22, no. 1 (1992): 27-37.

Hitch, Charles J., and Roland N. McKean. "The Economics of Defense in the Nuclear Age." Cambridge, MA: Harvard University Press (1967).

O’Neill, Robert. "Defense Policy." In Australia in World Affairs, 1971-1975, 24-25. Sydney: George Allen and Unwin, 1980.

Young, Thomas-Durell. "Problems in Australia's 'Defense Revolution." Contemporary Southeast Asia 11, no. 3 (1989): 237-56. 